\title{
Introduction to the business model innovations in emerging markets special issue
}

\author{
John Hulland ${ }^{1}$ - Mark Houston ${ }^{2}$ \\ Published online: 10 June 2020 \\ (C) Academy of Marketing Science 2020
}

Over the past decade, many emerging markets have seen profound changes in consumers' preferences for products and services. This shift has been influenced by a variety of factors, including political, economic, technological, sociological, and psychological drivers. From a marketing perspective, changing consumer preferences are also affected by the growing availability of many branded products at relatively lower prices, expanding distribution systems, and growing disposable income.

Despite significant resource limitations, emerging market firms have increasingly been able to provide innovative products and solutions to the entire world. In fact, emerging markets have been cited as a primary growth engine of the world economy. However, these firms are not consistently able to cope with the innovation demands they face. In particular, the growth of digital and social media has fundamentally changed the way in which consumers interact with firms. Thus, there is a need to look at how marketing-mix dynamics are changing, and what this shift means for emerging markets firms' business strategies.

In 2017, former Editor Rob Palmatier laid the plans for this special issue, inviting V. Kumar and Rajendra Srivastava to serve as Guest Editors. In their call for papers, Kumar and Srivastava indicted that they were interested in receiving papers focused on the broad topic of managing business and innovation in emerging economies. In conjunction with this call, JAMS sponsored a Thought Leaders' conference, "Managing Business and Innovation in Emerging Markets," held in April 2018 at the Indian School of Business (ISB) in Hyderabad, India. Although attendance at the conference was not a requirement for paper submission to the JAMS special issue, it was encouraged so as to provide authors with early feedback on their research. Over 120 submissions were received for the conference presentation and roughly 70 were selected for presentation based on the first round of screening. Feedback was provided on each conference presentation to enhance the contribution of the study for submission to the special issue.

Whereas the papers submitted to this special issue were generally processed by both guest editors, if there was any conflict of interest for one of the guest editors, the other assumed full responsibility for handling the manuscript. Furthermore, in select cases where additional editorial guidance was needed, the guest editors were able to confer with John Hulland in his role as Editor-in-Chief.

A total of 62 manuscripts were submitted to this special issue, with 10 ultimately selected for publication. Throughout this process, the comments received from reviewers were invaluable in helping to assess the merits of the submissions and in improving their quality. We are indebted to the individuals listed below for their generous investment of time and energy in making this special issue a reality.

John Hulland

jhulland@uga.edu

1 Department of Marketing, Terry College of Business, University of Georgia, Athens, GA, USA

2 Department of Marketing, Neeley School of Business, Texas Christian University, Fort Worth, TX, USA 
M. Billur Akdeniz

Todd Arnold

S. Arunachalam

Seigyoung Auh

Barry Babin

Cem Bahadir

Thomas Baker

Joshua Beck

Simon Bell

Neeraj Bharadwaj

Sundar Bharadwaj

Abhishek Borah

Sourav Borah

Douglas Bowman

Roger Calantone

Joseph Cannon

Brian Chabowski

Deepa Chandrasekaran

Sandeep Chandukala

Sharmila Chatterjee

Amitava Chattopadhyay

Victoria Crittenden

Gopal Das

Satyabhushan Dash

Mayukh Dass

John Deighton

Kalpesh Desai

Claudiu Dimofte

Michael Dorsch

Andreas Eggert

Tulin Erdem

Pantea Foroudi

Björn Frank

Ina Garnefeld

Dinesh Gauri
Tanuka Ghoshal

Kendall Goodrich

Ronald Goodstein

Shyam Gopinath

Yany Gregoire

Shaphali Gupta

Suraksha Gupta

Kelly Hewett

Ronald Hill

Ming-Hui Huang

Michael Hutt

Charles Ingene

Gopal Iyer

Shailendra Jain

Ram Janakiraman

Vamsi Kanuri

Constantine Katsikeas

Stephen Kim

Alexander Krasnikov

Sabine Kuester

Leonidas Leonidou

Barak Libai

Bryan Lukas

Donald Lund

Girish Mallapragada

Ashwin Malshe

Murali Mantrala

Charlotte Mason

Bulent Menguc

Fred Miao

Saurabh Mishra

Neil Morgan

Julie Moulard

Janet Murray

Kyle Murray
Cheryl Nakata

Patricia Norberg

Aysegul Ozsomer

Kiran Pedada

Stacey Robinson

Mark Rosenbaum

Subroto Roy

Gary Russell

Oliver Rutz

Alok Saboo

Arvind Sahay

Saeed Samiee

Lisa Scheer

G. Shainesh

Venkatesh Shankar

Amalesh Sharma

Ramendra Singh

Rebecca Slotegraaf

Ashish Sood

S. Sridharan

Lena Steinhoff

David Stewart

Elina Tang

Carlos Torelli

Rajan Varadarajan

Stephen Vargo

Kevin Voss

Joshua Wiener

Karen Winterich

Stefan Worm

Manjit Yadav

Jun Yan

Wei Zhang

Xubing Zhang

Yinlong Zhang

Publisher's note Springer Nature remains neutral with regard to jurisdictional claims in published maps and institutional affiliations. 